\title{
O CONTEXTO NEGACIONISTA E A RESISTÊNCIA DA COMUNIDADE CIENTÍFICA
}

\author{
ASPECTOS ASSOCIADOS À PANDEMIA NAS PROVAS DO ENADE DE 2021
}

\section{EL CONTEXTO NEGACIONISTA Y LA RESISTENCIA DE LA COMUNIDAD CIENTÍFICA}

Aspectos asociados a la pandemia en las pruebas ENADE 2021

\section{THE NEGATIONIST CONTEXT AND THE RESISTANCE OF THE SCIENTIFIC COMMUNITY}

Aspects associated with the pandemic in the 2021 ENADE tests

Ivy Judensnaider

(Universidade Paulista, Universidade Estadual de Campinas, Brasil)

ivy.naider@gmail.com

\begin{abstract}
Cristina Pontes Bonfiglioli
(Pontifícia Universidade Católica de São Paulo, Universidade de São Paulo, Brasil) cristina.bonfiglioli@gmail.com

Flaminio de Oliveira Rangel

(Universidade Federal de São Paulo, Brasil)

flaminio.rangel@gmail.com

Recibido: 07/01/2022

Aprobado: 04/02/2022
\end{abstract}

\section{RESUMO}

O debate sobre a inclusão de aspectos associados à pandemia no componente de Formação Geral nas provas do ENADE (Exame Nacional de Desempenho) de 2021 justifica-se em função de tal tema não estar contemplado pela base de itens comum a todos os cursos. Nesse sentido, entende-se que a inserção de temas associados à pandemia do coronavírus causador da Covid-19 no componente de Formação geral das provas do ENADE 2021 é um importante sinalizador dos temas percebidos como relevantes pelo Instituto Nacional de Estudos e Pesquisas Educacionais Anísio Teixeira (INEP), instituição responsável pela elaboração das provas do ENADE. Propomos que a inclusão deste conteúdo seja percebida como um movimento de resistência da comunidade acadêmica e dos técnicos do INEP ao ambiente negacionista que impregnou as áreas da Educação, Saúde e Ciência no Brasil.

Palavras-chave: ENADE. INEP. covid-19. pandemia. avaliação. ensino superior. 


\section{RESUMEN}

El debate sobre la inclusión de aspectos asociados a la pandemia en el componente de formación general en las pruebas ENADE (Examen Nacional de Rendimiento) 2021, se justifica por el hecho de que este tema no figura como posibilidad desde la base de ítems que son comunes a todos los cursos En ese sentido, se entiende que la inclusión de temas asociados a la pandemia del coronavirus que provoca el Covid-19 en el componente de Formación General de las pruebas ENADE 2021 es un indicador importante de los temas percibidos como relevantes por el Instituto Nacional de Estudios y Pesquisas Educacionais Anísio Teixeira (INEP), institución responsable de la elaboración de las pruebas de la ENADE. Proponemos que la inclusión de este contenido sea percibida como un movimiento de resistencia de la comunidad académica al ambiente negacionista que impregnaba las áreas de Educación, Salud y Ciencia en Brasil.

Palabras clave: ENADE. INEP. covid-19. pandemia. evaluación. enseñanza superior.

\section{ABSTRACT}

The debate on the inclusion of aspects associated with the pandemic in the General Training component of 2021 ENADE (National Performance Exam) tests is justified because this topic is not listed as a possibility from the base of standard items for all courses. In this sense, it is understood that the inclusion of topics associated with the pandemic of the coronavirus that causes Covid-19 in the General Training component of ENADE 2021 tests is an essential indicator of the topics perceived as relevant by the Instituto Nacional de Estudos e Pesquisas Educacionais Anísio Teixeira (INEP), the institution responsible for preparing ENADE tests. We propose that the presence of this content is perceived as a resistance movement by the academic community to the negationist environment that permeated the areas of Education, Health, and Science in Brazil.

Keywords: ENADE. INEP. covid-19. pandemic. evaluation. undergraduate courses.

\section{Introdução}

No Brasil, os cursos de Ensino Superior são avaliados em sistema de rodízio a cada três anos pelo SINAES (Sistema Nacional de Avaliação da Educação Superior). Como um dos indicadores da qualidade do ensino oferecido pelas instituições de Ensino Superior (IES), o desempenho dos alunos concluintes é avaliado por meio de uma prova, a assim chamada prova do ENADE (Exame Nacional de Desempenho dos Estudantes). Nesta prova, são propostos aos alunos concluintes 40 itens, sendo 10 de Formação Geral, 5 de Formação Pedagógica (para todos os alunos de cursos de licenciatura) e 25 de Formação Específica ${ }^{1}$.

Nosso texto discute a inclusão de temas associados à pandemia do coronavírus, causador da Covid-19, no componente de Formação Geral das provas do ENADE de 2021. A escolha por esse componente parece justificar-se por seu caráter comum a todos os cursos, o que nos permite entendê-lo como um importante sinalizador da relevância atribuída pelo INEP (Instituto Nacional de Estudos e Pesquisas Educacionais Anísio Teixeira), instituição responsável pela elaboração das provas do ENADE, aos temas que nele figuram. Assim, consideramos que a inclusão deste conteúdo possa sinalizar um movimento de resistência da comunidade acadêmica e dos técnicos do INEP ao negacionismo que provocou o insulamento de cientistas, universidades e pesquisadores.

\footnotetext{
${ }^{1} \mathrm{O}$ componente de Formação Geral é proposto nos termos de portaria específica. O componente de Formação Pedagógica é proposto por meio da portaria que regulamenta os conteúdos do curso de Pedagogia. Os conteúdos de formação específica são propostos em portarias específicas para cada um dos cursos avaliados.
} 
O texto está organizado em três seções: a) a importância do ENADE como forma de avaliar a qualidade de ensino oferecido pelas IES e a elaboração dos itens das provas; b) o histórico da pandemia no mundo e no Brasil, em especial com relação aos problemas e conflitos presentes na sociedade brasileira quando do seu enfrentamento; c) os conteúdos do componente de Formação Geral, tais como propostos pela portaria do INEP, e os itens de Formação Geral envolvendo temáticas sobre a pandemia do coronavírus ou a ela associadas.

\section{Os exames de larga escala e o ENADE}

As avaliações escolares em larga escala têm sido realizadas de forma sistemática com o objetivo de aferir, junto ao maior número possível de alunos, a apreensão de conteúdos relevantes ou o nível de desempenho quanto às principais competências e habilidades (Vianna, 2003) associadas à formação do alunado em questão. Em geral, são promovidas por órgãos governamentais, supostamente capazes de oferecer um "olhar" externo objetivo e imparcial. Para além dos objetivos de acompanhar o desempenho de alunos, estas avaliações também podem ser utilizadas como instrumento para o acesso ao ensino superior (como é o caso do ENEM) ou para efeito de accountability, ou seja, como forma de avaliar a qualidade de ensino oferecido pelas instituições escolares.

A década de 1990 marcou o início do período em que a realização de exames de larga escala passou a ser estimulada como forma de avaliar a capacitação da mão de obra formada pelas instituições encarregadas do Ensino Superior. Afinal, os exames poderiam fornecer informações importantes para os organismos internacionais financiadores, tais como o Banco Mundial, Fundo Monetário Internacional, a Organização para a Cooperação e o Desenvolvimento Econômico e o Banco Interamericano de Desenvolvimento, para citar alguns (Dias Sobrinho, 2010). De fato, no contexto do preconizado pelo Consenso de Washington, a estratégia de abrir espaço ao mercado (com a autorização para a abertura de cursos sob a gestão de instituições privadas) sugeria a constituição de instâncias reguladoras, em geral coordenadas pelo Estado.

Em 2003, o projeto do SINAES (Sistema Nacional de Avaliação da Educação Superior) buscou maior proximidade com as aspirações da comunidade acadêmica, propondo-se a incluir a avaliação de atributos e de processos mais associados a metas e práticas pedagógicas (Fernandes; Nazareth, 2011). Segundo Dias Sobrinho, o SINAES materializou "a aliança orgânica entre a regulação (...) e a avaliação, integrada por múltiplos instrumentos, e contando com a participação da comunidade acadêmico-científica, das autoridades das IES e de membros da comunidade civil" (Dias Sobrinho, 2010: 209). Assim, o processo de avaliação do SINAES buscou reunir informações a partir de várias frentes de avaliação e com a participação de múltiplos agentes: alunos, professores, coordenadores e CPAs (Comissões Próprias de Avaliação).

Embora essas mudanças tenham melhorado o sistema de avaliação como um todo, boa parte dos críticos aos exames de larga escala continuou a apontar problemas potenciais de provas desse tipo: o estreitamento do currículo (já que as IES buscariam priorizar apenas os temas abordados nos exames) e o gaming (a exclusão dos alunos de baixa proficiência por meio da seleção dos estudantes participantes das avaliações) (Fernandes; Gremaud, 2009). Em especial, as críticas diziam respeito ao fato de as IES utilizarem os resultados dos exames como forma de obter visibilidade na mídia, por meio de uma publicidade que transformaria notas elevadas (ou superiores às de outras instituições) em discursos mercadológicos (Fernandes; Nazareth, 2011; Barreyro, 2008). Entretanto, ainda que consideradas as limitações inerentes a quaisquer avaliações de larga escala, é inegável que o SINAES vem produzindo informação de qualidade para gestores, educadores, alunos e outros agentes do sistema educacional ${ }^{2}$.

\footnotetext{
${ }^{2}$ É importante ressaltar que, do ponto de vista das IES, uma boa colocação nos rankings é fundamental (Rocha; Ferreira, 2017), já que os resultados produzidos pelo SINAES determinam o acesso a recursos de convênios (FIES e PROUNI), a disponibilização ou não de recursos financeiros por parte das agências de fomento à pesquisa e à educação, e a autorização para a manutenção ou a criação de novos cursos de nível superior.
} 
Os itens apresentados nas provas do ENADE são fornecidos pelo Banco Nacional de Itens (BNI), que fornece insumos para os exames de larga escala realizados no Brasil. Esses itens são elaborados e revisados por educadores e pesquisadores escolhidos por meio de chamada pública, de forma a envolver a participação da comunidade educacional e acadêmica do país. "As chamadas públicas fazem parte de um processo mais amplo de estruturação da rede de colaboradores do Inep, que participam de capacitações, oficinas de elaboração e revisão, e painéis de revisão de itens" (INEP, 2021b).

A análise de provas anteriores mostra que os itens do ENADE têm formatos muito distintos de outros itens de avaliações de larga escala. Em geral, os textos-base são longos e constituídos de gráficos ou figuras com várias informações. Os enunciados, por sua vez, alternam diferentes estratégias, podendo envolver: a) a escolha da alternativa correta que melhor se associa ou responde a uma pergunta feita; b) a identificação de várias afirmativas corretas ou incorretas; e c) a identificação de proposições corretas e de relações de causalidade entre elas. Embora esse formato de item tenha se disseminado na comunidade acadêmica (tendo inaugurado, inclusive, uma categoria que se tornou conhecida como "questão do tipo ENADE"), itens construídos a partir de enunciados que pedem a avaliação simultânea de várias afirmativas ou a identificação de relações causais entre assertivas (verdadeiras ou não) têm sido alvo de críticas por parte de educadores e pesquisadores, já que eles tornam difícil localizar a origem do erro eventualmente cometido pelo estudante (Judensnaider, Figueirôa e Villar, 2021).

As provas do ENADE que deveriam ter acontecido em 2020 foram suspensas em função da pandemia. A avaliação foi retomada em 2021 em meio à adoção de inúmeras medidas sanitárias para a proteção dos alunos e de outros profissionais envolvidos. "Apesar do cenário pandêmico, a realização do exame contou com a presença de 75,4\% do total de inscritos (489.958) e aconteceu sem intercorrências. Nesta edição, o Enade avaliou estudantes concluintes de 8.009 cursos de 30 áreas do conhecimento" (INEP, 2021a) $)^{3}$.

\section{A pandemia do coronavírus no mundo e no Brasil}

Segundo a Organização Pan-Americana de Saúde (OPAS, 2021), o primeiro alerta a respeito da Covid19 surgiu ao final de 2019, quando foi identificada uma provável nova cepa de coronavírus em humanos dentre os casos de pneumonia na cidade de Wuhan, na China. A confirmação da existência de uma nova doença não tardou: nas primeiras semanas de 2020, a OMS (Organização Mundial de Saúde) confirmou o novo coronavírus, denominado SARS-CoV-2. O avanço de novos casos e óbitos fez com que a OMS buscasse coordenar esforços mundiais para a contenção da doença, para sua investigação e para o desenvolvimento de protocolos sanitários e vacinas.

Em função dos milhares de casos em vários países e regiões do mundo, a OMS declarou, em março, a existência de uma pandemia de Covid-19. Os dados de dezembro de 2021 já registravam 267.865.289 casos de Covid-19 no mundo (4.226.593 apenas nos últimos sete dias), dos quais 5.285.888 resultaram em morte (WHO, 2021).

A reação da comunidade internacional estimulou uma verdadeira corrida para a descoberta de uma vacina que pudesse fazer frente à doença. Em agosto de 2020, vários estudos já estavam sendo realizados e, desde que foram criadas, as várias vacinas disponíveis imunizaram milhões de habitantes. Dados de dezembro de 2021 apontavam que, no mundo, a cada 100 habitantes, 44,29 já estavam totalmente imunizados (WHO, 2021).

A proporção mundial da pandemia, a rapidez com que o vírus se espalhou, o modo súbito com que os serviços públicos de saúde foram sobrecarregados com casos de síndrome respiratória aguda grave (SARS), tanto em países desenvolvidos como em países em desenvolvimento, e a aparente demora na produção de informações confiáveis sobre a profilaxia, os efeitos secundários e o tratamento da nova

\footnotetext{
${ }^{3}$ Deve-se lembrar que, embora o desempenho na prova não determine qualquer punição ou benefício ao aluno, a presença na avaliação é obrigatória para a concessão do diploma pela IES na qual o estudante está matriculado.
} 
doença alimentaram um sem-número de fake news. A maior parte delas versava sobre supostas intenções conspiratórias da China (que teria espalhado o vírus para prejudicar a economia dos países em desenvolvimento) e sobre as vacinas, que poderiam conter chips para controle e vigilância das pessoas, entre outras narrativas pseudocientíficas. A desconfiança em relação aos centros de pesquisa, aos órgãos de representação internacional e às mídias convencionais incentivou o acesso a fontes duvidosas da $w e b$, o que provocou o aumento da desinformação e do negacionismo. Por conta desse contexto, algumas instituições mundiais reuniram esforços para combater os mitos e os boatos envolvendo a doença, em especial quanto aos métodos de profilaxia (uso de máscara e higiene constante das mãos) e à vacinação (Paho, 2021a; 2021b). Esse esforço, no caso de países governados por conservadores ideologicamente orientados à direita - como o Brasil - teve que superar significativos obstáculos e enfrentar inúmeras dificuldades.

O primeiro caso de Covid-19 no Brasil foi identificado no final de fevereiro de 2020: tratava-se de um homem de 61 anos que acabara de chegar de viagem da Itália, e que dera entrada em um hospital de São Paulo. Segundo a Agência Brasil (2021), no mês de março já tínhamos casos de transmissão comunitária, ou seja, o vírus já circulava na população ${ }^{4}$. A cisão entre o governo federal e os Estados e Municípios ocorreu em função de diferentes perspectivas em relação à obrigatoriedade do uso de máscaras e do isolamento social: enquanto o governo federal ainda minimizava os efeitos da pandemia e defendia que os cidadãos tinham o direito de escolher não usar máscara, os governadores e prefeitos trataram de buscar o apoio do Supremo Tribunal Federal (STF). Em abril de 2020, o STF reconheceu a competência de Estados, do Distrito Federal, dos Municípios e da União para a execução de ações de combate à pandemia. Essa decisão, portanto, autorizava que governadores e prefeitos decretassem lockdowns e obrigassem o uso de máscara em espaços públicos (Radio Senado, 2020). Apesar da rápida ação de governadores e prefeitos, os casos de contágio e de óbito se multiplicaram. As dezenas de milhares de mortes transformaram-se em centenas de milhares de mortos: de fevereiro de 2020 a dezembro de 2021, foram identificados 22.177.059 casos de contágio e 616.457 mortes por Covid-19 no Brasil (São Paulo, 2021).

No âmbito federal, o cargo de Ministro da Saúde mostrou-se de alta rotatividade: em quase dois anos, o Brasil teve quatro ministros da Saúde (Luiz Henrique Mandetta, Nelson Teich, Eduardo Pazuello e Marcelo Queiroga). Era quase impossível para o governo federal encontrar alguém respeitado pela comunidade médica que aceitasse ceder às diretrizes do presidente Bolsonaro quanto ao enfrentamento à pandemia (Senado Federal, 2021). Aliás, o presidente, de forma contínua, em entrevistas ou conversas com apoiadores à frente do Palácio do Planalto, continuava a negar a gravidade da situação, a fazer deboche de medidas sanitárias, a boicotar o isolamento social e o uso de máscara, a defender o uso de remédios ineficazes para uma suposta prevenção contra a Covid-19 (contrariamente à opinião da comunidade científica internacional), a defender uma estapafúrdia tese de imunidade de rebanho (ou seja, a imunidade que a sociedade alcançaria quando a maioria da população já tivesse contraído o novo coronavírus), a lançar suspeitas contra os centros de pesquisa e indústrias farmacêuticas envolvidas com os estudos sobre a doença, a difundir informações inverídicas e sem qualquer fundamentação científica e a boicotar, quase de forma explícita, a aquisição das vacinas que estavam disponíveis no mercado (inclusive a fabricada no Brasil com o uso de tecnologia chinesa) (Senado Federal, 2021). Tal panorama retardou os esforços para a testagem em massa, para a distribuição de recursos e materiais para o combate à pandemia e para o tratamento dos que haviam contraído a doença (Humanista, 2021). Ainda é importante mencionar que nem mesmo a área da Ciência, Tecnologia e Inovações, comandada pelo tenente-coronel Marcos Pontes, conseguiu agir de forma a mediar as tensões entre o governo e a sociedade civil, em especial entre as autoridades que, efetivamente, decidiam sobre as políticas de combate à pandemia, e a comunidade acadêmica e científica. Embora portador de um bacharelado em Ciências Aeronáuticas e Administração Pública, e tendo formação como engenheiro aeronáutico, além de mestrado em Engenharia de Sistemas, Pontes (que chegou ao governo carregando o título de primeiro - e único, até agora - astronauta brasileiro) não tomou quaisquer medidas visíveis de enfrentamento ao negacionismo, tampouco buscou minorar os embates entre as alas ideológicas do governo e as

${ }^{4}$ A transmissão comunitária ocorre quando há casos em que já não é possível rastrear a origem da contaminação. 
universidades, instituições de pesquisa e de avaliação da pesquisa e da aprendizagem em nível superior. Ao contrário, demorou a reagir à iniciativa do Ministério da Economia de desviar recursos destinados à Ciência para outras áreas, puniu servidores públicos de carreira por motivos obscuros, foi omisso em relação às necessidades de institutos de pesquisa quanto à aquisição de insumos para a continuidade dos trabalhos, não se mobilizou diante da iniciativa do Ministério Público em suspender a avaliação de programas de pós-graduação (SBPC, 2022).

Outra área marcada pelos embates ideológicos foi o da Educação: de forma semelhante ao que ocorreu no Ministério da Saúde, desde a posse do presidente Bolsonaro, os conflitos entre as alas do governo provocaram sucessivas mudanças na gestão do órgão. De janeiro de 2019 até a data em que este artigo foi redigido, três ministros ocuparam o cargo ${ }^{5}$. O primeiro foi Ricardo Vélez Rodrigues, bacharel em Humanidades e Filosofia, teólogo e professor (MEC, 2020). No dia de sua nomeação, Vélez publicou um texto no qual afirmava ser importante defender a educação brasileira de "uma doutrinação de índole cientificista e enquistada na ideologia marxista". Ao invés de educação sexual e "ideologia de gênero", iria privilegiar a "preservação da vida, da família, da religião, da cidadania, em soma, do patriotismo" (El País Brasil, 2018). Vélez permaneceu no cargo por três meses. O segundo Ministro da Educação foi Abraham Weintraub. Professor da UNIFESP e economista, já havia participado da equipe de campanha do então candidato Bolsonaro (MEC, 2020). Em abril de 2019, ordenou o contingenciamento de verbas das universidades federais, paralisando o pagamento de bolsas e forçando a interrupção de projetos de pesquisa. Posteriormente, Weintraub foi chamado pela Comissão de Educação da Câmara dos Deputados para prestar contas de sua declaração de que, nas universidades federais, existiam extensas "plantações de maconha" (BBC Brasil, 2020b). Em abril de 2020, em meio aos milhares de doentes e de óbitos, Weintraub debochou da China, afirmando ser a pandemia uma ação orquestrada por aquele país para dominar o mundo. Milton Ribeiro, pastor presbiteriano, criacionista e teólogo, assumiu o Ministério em julho de 2020 como resultado do lobby da ala evangélica alinhada ao governo federal. Profissional da área da Educação, seu histórico incluía estreitos laços com a Universidade Presbiteriana Mackenzie, instituição privada de São Paulo conhecida por defender a teoria do design inteligente como alternativa "cientificamente válida" à teoria darwiniana da seleção natural (ABCC, 2017).

O INEP, responsável pela elaboração e aplicação de exames de larga escala, sofreu as consequências das constantes mudanças no Ministério. Desde janeiro de 2019, cinco presidentes comandaram o órgão: Maria Inês Fini, uma das idealizadoras da prova do ENEM e que havia sido nomeada no governo anterior, foi demitida assim que o governo Bolsonaro assumiu; Marcus Vinicius Rodrigues permaneceu no posto por três meses; Elmer Vicenzi ficou só 18 dias no cargo; Alexandre Lopes permaneceu como presidente do INEP durante nove meses. Danilo Dupas Ribeiro, empossado em março, é o atual presidente, e sua gestão também tem sido marcada por problemas: nos últimos dois meses de 2021, em meio à realização das provas do ENADE e do ENEM, o INEP viu 37 de seus técnicos pedirem exoneração em função de discordância e insatisfação com os rumos que a área estava tomando (Globo G1, 2021). No início de 2022, outro problema surgiu: o diretor de Gestão e Planejamento do INEP, após a realização do ENEM 2021, foi exonerado, possivelmente por conta de uma atuação marcada pela resistência ao atendimento dos planos do governo, e já buscando sobreviver num ambiente de tentativas sucessivas de interferência nos exames do INEP e de denúncias de servidores por assédio moral (Folha de São Paulo, 2022).

Considerando a conjuntura aqui tratada, nosso objetivo é refletir sobre a forma como o tema da pandemia foi tratado na prova do ENADE em 2021. Ainda, o debate que propomos é o de pensar se a inclusão de temas associados à pandemia - e a forma como essa inclusão foi realizada - podem servir de sinalizadores de um movimento de resistência da comunidade acadêmica e dos técnicos do INEP ao desejo, por parte do Governo Federal, de se fazer representar ideologicamente nas provas do ENADE. Nas seções seguintes, veremos quais conteúdos estavam previstos para o componente de Formação Geral e quais itens, entre os propostos nas provas de 2021, envolveram a temática relacionada à pandemia.

${ }^{5}$ Teríamos tido quatro, caso a nomeação de um deles não tivesse sido cancelada por conta da descoberta de informações inverídicas no seu currículo profissional. 


\section{Os conteúdos do componente de Formação Geral nas provas do ENADE de 2021 e os itens sobre a pandemia}

Os objetivos referentes à aplicação de itens de caráter geral e os temas a serem tratados no componente de Formação Geral no ENADE de 2021 foram apresentados na Portaria 386 do INEP (Brasil, 2021). Nas provas do ENADE de 2021, tal como ocorreu em outros anos, o componente de Formação Geral compreendeu 10 itens, sendo 8 de múltipla escolha e 2 de caráter dissertativo. Este componente foi responsável por $25 \%$ da nota final atribuída ao aluno. O componente previa, como características desejáveis do egresso, o comprometimento com a ética e com questões sociais, culturais e ambientais; o comprometimento com o exercício da cidadania; a crítica humanista com base no conhecimento científico historicamente construído; a proatividade e a solidariedade na tomada de decisões; e a colaboração e proposição no trabalho em equipes (em especial no tocante ao respeito às diferenças). Como competências, seriam avaliadas aquelas associadas ao fomento do diálogo e de práticas de convivência; à busca por soluções inovadoras; à sistematicidade e à análise de informações para a tomada de decisões; ao planejamento e à elaboração de projetos de ação e intervenção; à compreensão das linguagens (verbais e não verbais); à articulação de argumentos e contra-argumentos e ao estabelecimento de relações de causalidade (Brasil, 2021).

De acordo com o Art. $6^{\circ}$. da Portaria 386, os componentes de Formação Geral tomariam como referencial os seguintes temas:

I - Ética, democracia e cidadania;

II - Estado, sociedade e trabalho;

III - Educação e desenvolvimento humano e social;

IV - Cultura, arte e comunicação;

V - Ciência, tecnologia e inovação;

VI - Promoção da saúde e prevenção de doenças;

VII - Segurança alimentar e nutricional;

VIII - Meio ambiente: biodiversidade, sustentabilidade e intervenção humana;

IX - Cidades, habitação e qualidade de vida;

$\mathrm{X}$ - Processos de globalização e política internacional;

XI - Sociodiversidade e multiculturalismo;

XII - Acessibilidade e inclusão social (Brasil, 2021).

Todos os temas sugeridos na Portaria poderiam remeter ou ser associados a situações vividas pela sociedade brasileira ao longo de quase dois anos de pandemia. A questão da desigualdade social; a necessária intervenção do Estado no sentido de garantir uma renda mínima para os segmentos economicamente mais vulneráveis da sociedade; o reconhecimento da importância de serviços públicos de saúde; a admissão de que a degradação ambiental poderia colocar o futuro da espécie humana em risco; e o negacionismo em relação à ciência e a suas instituições, todos esses foram elementos a respeito dos quais o corpo social brasileiro teve que refletir quando da mobilização de esforços para o enfrentamento à pandemia. Resta-nos, portanto, responder de que maneira o tema da pandemia compareceu nos itens do componente de Formação Geral das provas do ENADE de 2021. Apesar de buscarmos indícios no texto dos itens presentes no componente de Formação Geral que claramente tratam da pandemia, nossa análise é de interpretação sociocultural. Em outros termos, propomos discutir mais abertamente de que forma o arcabouço institucional representado pelas Portarias pode ter determinado o conteúdo das questões das provas do ENADE, numa resposta às tensões políticas nas áreas da Educação, da Saúde e da Ciência nos últimos três anos.

Dentre os dez itens de Formação Geral, dois estão especificamente relacionados ao contexto da pandemia. Um item fez referência aos diferentes impactos que a pandemia causou em termos de expectativa de vida dos norte-americanos, considerando-se os grupos étnicos (brancos, negros e latinoamericanos); o outro, tratou de relações entre tecnologia, busca por informações a respeito de saúde e adoção de hábitos saudáveis. Embora o segundo item não tenha relação direta com a pandemia, os seus 
conteúdos envolvem questões que foram (e ainda são) intensamente debatidas na sociedade, em especial quanto às fake news e às campanhas de desinformação realizadas por setores políticos mais conservadores. A seguir, apresentamos cada item e a análise realizada a respeito do conteúdo que nele foi proposto.

\section{O item FG01}

O texto-base do item a partir de agora denominado FG01 reproduz um trecho de uma reportagem da Revista EXAME, publicada em 2021. São mencionados os impactos econômicos da pandemia no mundo todo e são discutidos os resultados de um estudo no qual os pesquisadores observaram uma queda na expectativa de vida dos norte-americanos, em função da pandemia. Segundo os dados da pesquisa, observaram-se diferentes níveis de redução de expectativa de vida, em função da etnia do grupo analisado. Nesse sentido, o estudo evidenciou que a redução era maior entre os latinos e negros, nessa ordem.

O enunciado envolve identificar como corretas ou não duas assertivas; e apontar a existência ou não de uma relação causal entre elas, caso percebidas como corretas. A primeira assertiva afirma que há relação entre situação de vulnerabilidade social e os diferentes efeitos da pandemia da Covid-19; a segunda aventa a hipótese de que os níveis diferentes de impacto na expectativa de vida por etnia devem-se às distintas condições de trabalho de negros e latino-americanos, o que levaria a diferentes níveis de exposição à doença.

As alternativas alternam a identificação das afirmativas como corretas ou incorretas, e sugerem diferentes relações de causalidade entre elas. O gabarito indica as duas assertivas como verdadeiras, sendo a segunda uma justificativa correta da primeira, ou seja, o fato de existirem diferentes condições de trabalho em diferentes grupos étnicos (quer dizer, de existirem diferentes níveis de vulnerabilidade social) justifica os diferentes impactos da pandemia quando considerados grupos étnicos distintos. A seguir, apresentamos o item FG01.

\section{Item FG01}

A pandemia ocasionada pelo novo Coronavírus gerou impactos negativos na economia e nos negócios, intensificando problemas sociais no mundo todo. Nos Estados Unidos, um estudo realizado com a parceria de duas importantes universidades verificou que a expectativa de vida dos norte-americanos caiu 1,1 ano em 2020. A nova expectativa é de 77,4 anos. De acordo com o estudo, esta foi a maior queda anual da expectativa de vida já registrada nos últimos 40 anos. O declínio é ainda maior se considerada a expectativa de vida para negros que moram no país, cuja queda foi de 2,1 anos. Para a população latina, essa queda foi de 3 anos. O declínio na expectativa de vida dos latinos é significativo, uma vez que eles apresentam menor incidência de condições crônicas que são fatores de risco para a Covid-19 em relação às populações de brancos e negros.

Loureiro, R. Covid-19 reduz gravemente expectativa de vida de negros e latinos nos EUA. Revista Exame, 2021 (adaptado).

Considerando as informações apresentadas no texto, avalie as asserções a seguir e a relação proposta entre elas.

I. O efeito desproporcional da pandemia da Covid-19 na expectativa de vida da população negra e latinoamericana estabelece relação com sua situação de vulnerabilidade social.

PORQUE

II. Uma hipótese que pode ser levantada quanto à diminuição da expectativa de vida de negros e latinoamericanos está relacionada às suas precárias condições de trabalho, levando-os a maior possibilidade de exposição ao contágio pelo novo Coronavírus.

A respeito dessas asserções, assinale a opção correta.

a) As asserções I e II são proposições verdadeiras, e a II é uma justificativa correta da I.

b) As asserções I e II são proposições verdadeiras, mas a II não é uma justificativa correta da I.

c) A asserção I é uma proposição verdadeira, e a II é uma proposição falsa. 
d) A asserção I é uma proposição falsa, e a II é uma proposição verdadeira.

e) As asserções I e II são proposições falsas.

Gabarito: A.

Como é possível perceber, o item aborda alguns importantes fenômenos sociais decorrentes da pandemia. Embora o exemplo citado seja de um estudo realizado nos Estados Unidos (e que envolve, portanto, dados referentes àquela sociedade), o item aborda resultados que se repetiram em todos os lugares do mundo, quais sejam, o de que a vulnerabilidade social determinou os níveis de impacto da pandemia, e o de que a vulnerabilidade social esteve associada a inúmeras variáveis, dentre elas a etnia.

No Brasil, as primeiras medidas tomadas por prefeitos e governadores no combate à pandemia incluíram a recomendação de isolamento e distanciamento social, o fechamento das escolas, as restrições para o comércio e o uso de máscara em locais públicos. Demorou para que a sociedade brasileira percebesse que essas eram medidas que não alcançavam a todos: os que viviam da prestação de serviços diários (funcionários de limpeza, pedreiros, trabalhadores da construção civil, ambulantes e entregadores) estavam na informalidade e não tinham como trabalhar remotamente. Mesmo alguns trabalhadores do setor formal não tinham como trabalhar à distância: atendentes de farmácias, bancos e supermercados, motoristas de ônibus e, é claro, todos os profissionais da área da saúde. A continuidade das atividades escolares só era possível nos domicílios em que havia acesso à internet e dependia da disponibilidade de computadores na residência. O problema do distanciamento social também não era algo fácil de ser resolvido para boa parte dos habitantes dos centros urbanos: os mais vulneráveis do ponto de vista social moravam em condições extremamente precárias, incapazes de manter qualquer distância em relação aos demais moradores na residência.

O enfrentamento à pandemia de Covid-19 tinha que levar em conta que somos um país de imensas desigualdades sociais (Atlas Brasil, 2021; IBGE, 2021a; 2021b). Como adotar medidas que protegessem a todos? E, caso todos não estivessem protegidos, como interromper a circulação do vírus? Essas foram perguntas que a sociedade brasileira teve que responder: afinal, os dados comparativos entre número de casos e óbitos mostravam a desvantagem de homens pretos e mulheres pretas (dentre os quais a proporção de mortes era maior do que a existente nos grupos de pessoas brancas), de moradores de bairros de baixa renda, dos que dependiam dos serviços prestados pela rede pública de saúde (onde o índice de recuperação era menor, comparativamente à rede privada), dos que dependiam do trabalho diário para prover a família e dos que não tinham renda suficiente para a compra de máscaras e álcool em gel (RNSP 2020; 2021).

O quadro de desigualdade já era conhecido. Segundo o Atlas Brasil (2021), no ano de 2017, no Maranhão, $10,38 \%$ da população já havia sido internada por doenças relacionadas ao saneamento ambiental inadequado; em comparação, no estado de São Paulo essa condição atingia apenas 0,7\% da população. Em 2017, no Amapá, apenas 39\% das crianças nascidas vivas tinham tido suas mães atendidas em, pelo menos, sete consultas de pré-natal; no Paraná, essa proporção era de $84 \%$ (Atlas Brasil, 2021). Em 2017, uma criança nascida no Maranhão tinha uma expectativa de vida de 70 anos; uma criança nascida em Santa Catarina, 79 (IBGE, 2021a). Em 2018, no Brasil, 41,5\% de pessoas de 14 anos ou mais de idade estavam trabalhando em ocupações informais no momento da pesquisa; dentre a população branca, essa proporção era de $34,6 \%$; entre pretos e pardos, $47,3 \%$. No mesmo ano, na Região Norte, $51,7 \%$ das pessoas brancas de 14 anos ou mais estavam em ocupações informais; no caso dos pretos e pardos, essa proporção era de $61 \%$ (IBGE, 2021b).

Consideremos o estado de São Paulo, cujo PIB (Produto Interno Bruto) era, em 2019, de aproximadamente US\$ 600 bilhões, "maior que o de países como Polônia, Suécia, Bélgica, Argentina, Âustria, Noruega, Irlanda, Singapura e Dinamarca" (Casa Civil SP, 2020). É neste estado que está localizado o município que mais contribui para o PIB do país, o município de São Paulo que, em 2019, foi responsável por 10,3\% do PIB do Brasil (IBGE, 2021c). Apesar da riqueza e da pujança, a cidade 
mais rica do estado mais rico da federação foi, também, o cenário de imensas desigualdades sociais. Em edição extraordinária do "Mapa de Desigualdades", a RNSP (2020) declarou haver:

evidências de que o impacto da pandemia se relaciona com as vulnerabilidades e desigualdades territoriais e que a qualidade de vida e longevidade são aspectos que podem influenciar esses números. Os distritos onde as pessoas vivem mais tempo, são os que têm melhores condições de vida e onde as mortes por Covid19 estão crescendo pouco. Na outra ponta, nos distritos onde as pessoas vivem menos tempo, encontra-se também piores condições de vida e é onde as mortes por coronavírus estão crescendo consideravelmente desde o começo da pandemia.

(...)

Apesar dos dados desagregados de óbitos da população negra ainda não serem divulgados, é possível compreender com graus de associação relevante, de que, os falecimentos de Covid-19 afetam mais a população negra, já que os distritos que representam os maiores números de mortes também são os que concentram a maioria da população negra, e na mesma linha, os distritos com os menores números de óbitos pela pandemia são também os que concentram números muito reduzidos de residentes pretos e pardos.

(...)

Os 11 distritos que não reúnem domicílios em favelas, de acordo com dados oficiais, têm baixo número de óbitos por Covid-19, em comparação com a média da cidade. [...] Os dois distritos que têm mais falecimentos por Covid-19 têm o percentual de domicílios em favelas 3 vezes maior que a média da cidade. Brasilândia e Sacomã têm 30\% e 28\% de seus domicílios em favelas (RNSP, 2020).

A interpretação do texto do item permite-nos concluir que, apesar de envolver dados referentes à realidade norte-americana, ele apresenta uma grande aderência aos problemas que a sociedade brasileira enfrentou no cenário pandêmico. Não apenas o item aborda os diferentes impactos da pandemia em função de condições de trabalho e de qualidade de vida para distintos grupos sociais, mas também se propõe a refletir sobre as relações de causalidade entre vulnerabilidade socioeconômica e maior exposição aos efeitos negativos da pandemia.

\section{O item FG02}

O item FG02 envolve as relações entre a adoção de hábitos saudáveis e a busca de informações sobre saúde na internet. São dois textos-base: o primeiro, citando informações de um estudo norte-americano, diz respeito à busca de informações na internet e a comportamentos relacionados à saúde, em especial na busca por diagnósticos precoces de doenças e enfermidades; o segundo, com base em pesquisas realizadas no Brasil, fala sobre o hábito de utilizar a internet como fonte confiável para dúvidas de natureza médica, o que tem feito aumentar o índice de autodiagnóstico e automedicação. Os dois textos, embora tragam exemplos positivos do uso da web para a coleta de informações, também mencionam alguns aspectos negativos desse comportamento, em particular no que respeita à falta de critérios dos usuários na escolha de fontes. $\mathrm{O}$ enunciado do item apresenta três assertivas sobre os textos e as alternativas solicitam que sejam identificadas quais as assertivas estão corretas. A seguir, apresentamos o item FG02.

\section{Item FG02}

\section{TEXTO I}

O estudo Internet and American Life Project, do Pew Research Center, demonstrou que, em 2009, metade das buscas de temas relacionados à saúde na internet era feita para terceiros, e quase seis em cada dez pessoas que usaram meios digitais para se informar sobre saúde mudaram o enfoque com que cuidavam da própria saúde ou da de algum parente. Estima-se que exista uma correlação positiva entre o grau de conhecimento das doenças (seus fatores de risco, formas de prevenção e tratamento) e a taxa de adoção de hábitos saudáveis pela sociedade. $\mathrm{O}$ aumento nos diagnósticos precoces do câncer de mama e a diminuição do tabagismo são dois exemplos clássicos a favor dessa ideia. Acredita-se que indivíduos mais bem informados aderem a comportamentos preventivos e reagem melhor a uma enfermidade. Infelizmente, a divulgação de temas médicos é uma faca de dois gumes: quem não sabe nada está mais perto da verdade do que a pessoa cuja mente está cheia de informações equivocadas. Conseguir que a mensagem seja bem decodificada pelos receptores é o grande desafio que preocupa (ou deveria preocupar) tanto médicos quanto jornalistas. 


\section{TEXTO II}

Tabakman, R. A saúde na mídia: medicina para jornalistas, jornalismo para médicos. Trad. Lizandra Magon de Almeida. São Paulo: Summus Editorial, 2013 (adaptado).

De acordo com os dados da última TIC Domicílios — pesquisa realizada anualmente com o objetivo de mapear formas de uso das tecnologias de informação e comunicação no país - , aproximadamente $46 \%$ dos usuários de Internet no Brasil utilizam a rede à procura de informações médicas sobre saúde em geral e serviços de saúde. Para uma médica e pesquisadora da Fiocruz, os indivíduos sempre procuraram informações sobre seu estado de saúde, mas é inegável que o surgimento da Internet trouxe um aumento significativo do acesso a informações amplificando assim os reflexos deste processo e alterando a relação entre os indivíduos. A pesquisadora chama a atenção para o perigo do autodiagnóstico e da automedicação, que podem gerar consequências nefastas tanto para os indivíduos quanto para a saúde pública, uma vez que boa parte dos estudos mostra que não são adotados critérios durante as buscas na Internet.

Disponível em: https://agencia.fi ocruz.br/conteudos-sobre-saude-na-webalteram-relacao-médico-paciente. Acesso em: 16 abr. 2020 (adaptado).

Considerando a abordagem dos textos, avalie as afirmações a seguir.

I. Os textos I e II evidenciam a importância de critérios nas buscas realizadas pelos usuários da Internet por informações sobre patologias, pois algumas informações podem trazer riscos à saúde por fomentarem a compreensão equivocada de sintomas e profilaxias.

II. O texto I afirma que a disponibilização de informações sobre temas de saúde nos meios de comunicação tem contribuído para o esclarecimento da população acerca de hábitos saudáveis.

III. No texto II, defende-se o acesso a informações relativas a pesquisas da área da saúde nos veículos de comunicação, pois elas permitem que o indivíduo seja proativo na prevenção de patologias.

É correto o que se afirma em
a) I, apenas.
b) III, apenas.
c) I e II, apenas.
d) II e III, apenas.
e) I, II e III.

Gabarito: C.

Como é possível aventar, a formulação do item pode ter induzido os estudantes ao erro: há dois textos, I e II; há três assertivas, I, II e III; há cinco alternativas que identificam as assertivas verdadeiras. O fato de o item fazer uso da mesma numeração para os textos e para as assertivas pode ter confundido os respondentes. Apenas para exemplificar, tomemos o caso da alternativa c: essa alternativa indica como verdadeiras as assertivas I e II. A assertiva I faz referência aos textos I e II; a assertiva II faz referência ao texto I. Assim, caso o aluno tenha errado, resulta ser de extrema dificuldade identificar qual raciocínio errado pode ter levado à escolha da alternativa incorreta.

Embora o item não trate diretamente da pandemia, é plausível estabelecer relações entre o que nele está sendo abordado e vários dos problemas enfrentados pela sociedade ao longo dos últimos dois anos, em especial a disseminação de notícias falsas via internet. Segundo Falcão e Souza (2021), a sociedade em rede tem seu funcionamento estruturado em termos globais e, nela, os múltiplos emissores de informação têm os instrumentos necessários para divulgar e disseminar o que consideram verdade, relativizando-a. Não à toa, a segunda metade do século XXI consagrou a Era da Pós-verdade, "período em que decisões tomadas por apelos emocionais parecem ter mais peso do que aquelas motivadas por fatos objetivos" (Falcão e Souza, 2021: 57). Este cenário se sustenta na desordem e na promoção da desconfiança em relação às instituições e aos meios de comunicação tradicionais, alimentando a crença de que a verdade pode ser escolhida em função do que se quer acreditar, ou melhor, que a verdade pode ser escolhida em função de crenças pessoais, independentemente de quaisquer evidências científicas. Com base nas ideias de Castells, Falcão e Souza (2021) esboçam as condições que estimulam o ambiente da pós-verdade:

as sociedades em geral têm sofrido com múltiplas crises, a saber: uma crise econômica que se prolonga em precariedade de trabalho e em salários de pobreza; um terrorismo fanático que fratura a convivência humana, alimenta o medo e dá amparo à restrição da liberdade em nome da segurança; as permanentes ameaças de guerras atrozes como forma de lidar com os conflitos; uma violência contra as mulheres que ousaram ser elas mesmas; uma galáxia de comunicação dominada pela mentira; a ausência de privacidade, na qual nos transformamos em dados; e uma cultura denominada entretenimento e construída sobre o estímulo de nossos baixos instintos e a comercialização de nossos demônios (Falcão; Souza, 2021: 58). 
A negação da ciência (por meio de informações que negam o aquecimento global e a chegada do Homem à Lua, por exemplo) e a destruição das reputações de instituições de pesquisa ou de representação internacional (como a OMS) são efeitos do mundo da pós-verdade. Segundo Falcão e Souza (2021), se a "infodemia" é a propagação excessiva de informações e a desinformação é o vazamento intencional de informações enganosas, podemos concluir que o contexto da pandemia de Covid-19 acabou por criar as condições necessárias para o surgimento de uma "desinfodemia", ou seja, uma campanha de desinformação excessiva, em geral comandada por grupos conservadores de extrema direita.

\begin{abstract}
Os temas das fake news relacionadas à Covid-19 são: a) origem e propagação do vírus; b) estatísticas falsas e enganosas; c) impactos econômicos (e sanitários) da pandemia; d) descrédito dos jornalistas e dos meios de comunicação; e) ciência médica: sintomas, diagnóstico e tratamento; f) impactos na sociedade e no meio ambiente; g) politização com ponto de vista; h) conteúdos promovidos para lucro fraudulento, a partir dos dados pessoais; e i) sobre celebridades que supostamente foram contaminadas (Falcão; Souza, 2021: 64).
\end{abstract}

No mundo em rede, a internet e as redes sociais potencializaram a disseminação de fake news; e com tal sucesso que acabaram por contribuir para a redução dos índices de imunização da população por meio de campanhas contrárias à vacinação. Durante a pandemia, esta ação provocou danos maiores, já que foram inúmeras as informações falsas disseminadas. Apenas para exemplificar, podemos citar notícias que afirmaram que o coronavírus poderia ser combatido (ou prevenido) com a ingestão de café, de chá de limão com bicarbonato, de água a cada quinze minutos, de alimentos alcalinos, de chá de erva-doce, de água com alho, de chá de abacate com hortelã e de uísque e mel (Falcão; Souza, 2021). Algumas medicações também foram alçadas à categoria de milagrosas formas de prevenção e cura da Covid-19, dentre elas a hidroxicloroquina, a ivermectina, o zinco e a ozonioterapia por via retal. Também foi divulgado que o feijão da Igreja Mundial desativava o coronavírus e que a OMS recomendava "evitar sexo desprotegido com animais" (Barcelos et al., 2021). Informações falsas sobre os métodos profiláticos também invadiram as redes sociais, como as que afirmavam que o álcool em gel não funcionava como forma de prevenção e que o termômetro digital infravermelho causava câncer e cegueira (Barcelos et al., 2021).

As campanhas de desinformação buscaram desacreditar os softwares utilizados pela área da Saúde para controle do número de casos e óbitos, insinuando que os aplicativos, quando instalados, poderiam extrair informações pessoais dos celulares. Aliás, a campanha para desacreditar os órgãos oficiais e os meios de comunicação chegou a divulgar que caixões vazios estavam sendo enterrados apenas para apavorar a população e superestimar o número de mortos por Covid-19 (BBC Brasil, 2020a). O próprio presidente brasileiro auxiliou na disseminação de notícias falsas sobre o suposto superdimensionamento das mortes, estimulando a população a invadir hospitais e "comprovar" a inexistência de doentes internados (Folha de São Paulo, 2020).

Outras notícias fizeram ostensiva campanha contra as vacinas, afirmando que elas disseminariam outras doenças (como o HIV, por exemplo, ou pneumonia e infertilidade masculina) (Falcão; Souza, 2021). O presidente brasileiro colaborou para a desinformação:

\footnotetext{
"Lá no contrato da Pfizer, está bem claro, nós (a Pfizer) não nos responsabilizamos por qualquer efeito colateral. Se você virar um jacaré, é problema seu”, disse Bolsonaro, que questionou em várias ocasiões as vacinas e a gravidade da pandemia que já deixou quase 185 mil mortos no Brasil. "Se você virar SuperHomem, se nascer barba em alguma mulher aí, ou algum homem começar a falar fino, eles (Pfizer) não têm nada a ver com isso. E, o que é pior, mexer no sistema imunológico das pessoas", continuou Bolsonaro em evento realizado nesta quinta-feira na Bahia (ISTO É, 2020).
}

A análise do item FG02 nos leva a concluir sobre a existência de uma clara aderência de seu conteúdo à realidade pandêmica brasileira, assim como os conteúdos previstos pelo INEP para o componente de Formação Geral. Tal como ocorreu no item anterior, os dados apresentados não dizem respeito única e exclusivamente ao Brasil. De fato, sequer fizeram referência direta à questão da pandemia. No entanto, é inegável que os temas discutidos no item são significativamente importantes e relevantes no atual contexto de enfrentamento à Covid-19. 


\section{Considerações Finais}

Os itens envolvendo aspectos relativos ao contexto da pandemia representam $25 \%$ da prova de Formação Geral, o que indica a importância que o INEP atribuiu ao tema e evidencia a disposição dos formuladores de incluir essa temática na prova.

Discutimos, ainda, como esses itens podem estar relacionados aos conflitos e aos embates ocorridos no Brasil nos últimos dois anos, ainda que a pandemia não estivesse listada explicitamente como possibilidade de componente para o ENADE 2021. Nossa análise textual indica que, ao tratarem dos diferentes impactos da pandemia, em função de distintos graus de vulnerabilidade social, e ao abordarem as relações entre a qualidade da informação e a adoção de comportamentos relacionados à saúde, os itens envolveram tópicos que foram (e ainda são) alvo de intensos embates e discussões na sociedade brasileira.

Chama a atenção o fato de os dois itens abordarem situações que não tiveram apenas o Brasil como referência: no caso do item FG01, o texto-base tratou da realidade norte-americana; e um dos textos do item FG02 remeteu a um estudo também norte-americano. Podemos aventar que esta escolha tenha sido estratégica, com o objetivo de deslocar o problema de um cenário única e exclusivamente brasileiro e, assim, imprimir mais autoridade aos argumentos apresentados nos textos-base; e, ao mesmo tempo, proteger os formuladores da prova. Afinal, não podemos esquecer que o clima de beligerância e intolerância que contaminou as áreas da Saúde e da Educação, no Brasil, tem gerado movimentos persecutórios contra cientistas e instituições, várias vezes colocados na posição de alvos preferenciais das milícias digitais que defendem as pautas do governo diante da opinião pública.

Os itens sobre a pandemia remetem a conflitos e discussões do momento social e político do País. Considerando, de um lado, a apropriação ideológica que setores mais conservadores realizaram das narrativas sobre a pandemia, e, de outro, os muitos sinais de inconformidade da sociedade civil, podemos supor que a prova do ENADE se insere numa estratégia de resistência ao negacionismo e de luta da comunidade acadêmica pelo pleno exercício da cidadania. De acordo com nossa análise, a prova parece reverberar as reações de apoio da sociedade brasileira à área científica e às suas instituições. Apesar dos cortes de verbas e da perseguição política, o Instituto Butantã e a Fundação Oswaldo Cruz (FIOCRUZ) foram bem-sucedidos na pesquisa e na oferta de vacinas. Não obstante à forte campanha do governo contra a vacinação, aproximadamente $70 \%$ da população brasileira já está vacinada. Em que pesem as fake news e o negacionismo presente nas instituições de Estado, os índices de vacinação mostram que a população não está afinada com a ojeriza à Ciência promovida pelo governo federal e por seus aliados. Ainda que houvesse o desgoverno e as descontinuidades no Ministério da Educação e no INEP, os formuladores da prova do ENADE de 2021 estariam defendendo a Ciência, a necessária seriedade dos meios de comunicação na difusão de informações científicas e a urgência de combatermos a desigualdade social.

\section{Referências}

ABCC Associação Brasileira de Cristãos na Ciência. (2021). Discovery-Mackenzie: Design Inteligente no Brasil. Disponível em: <https://www.cristaosnaciencia.org.br/discovery-mackenzie-designinteligente-no-brasil/>; acesso em: $19 \mathrm{dez} .2021$.

Agência Brasil. (2021). Primeiro caso de covid-19 no Brasil completa um ano. Brasil. DF, 2021. Disponível em: <https://agenciabrasil.ebc.com.br/saude/noticia/2021-02/primeiro-caso-de-covid-19no-brasil-completa-um-ano>; acesso em: 18 dez. 2021.

Atlas Brasil. Consulta. (2021). Atlas do Desenvolvimento Humano no Brasil: PNUD; Fundação João Pinheiro; IPEA Instituto de Pesquisa Econômica Aplicada, 2021. Disponível em: <http://www.atlasbrasil.org.br/consulta>; acesso em: 25 dez. 2021. 
Barcelos, Thainá do Nascimento de et al. (2021). Análise de fake news veiculadas durante a pandemia de COVID-19 no Brasil. Revista Panamericana de Salud Pública, v. 45: e65, 2021. Disponível em: <https://www.scielosp.org/article/rpsp/2021.v45/e65/pt/>; acesso em: 26 dez. 2021.

BBC Brasil. (2021). A farsa dos caixões vazios usados para minimizar mortes por covid-19. Maio de 2020. Disponível em: 〈https://www.bbc.com/portuguese/brasil-52584458>; acesso em: 26 dez. 2021.

BBC Brasil. (2021) Weintraub deixa o governo: seis polêmicas que marcaram a gestão no Ministério da Educação. Junho de 2020. Disponível em: 〈https://www.bbc.com/portuguese/brasil-53058067>; acesso em: 19 dez. 2021.

Brasil. Portaria INEP no. 386, de 23 de agosto de 2021. (2021). Ministério da Educação, Instituto Nacional de Estudos e Pesquisas Educacionais Anísio Teixeira, Brasília, DF, 2017. Disponível em: <https://www.in.gov.br/en/web/dou/-/portaria-n-386-de-23-de-agosto-de-2021-340157960>. Acesso em: 12 dez. 2021.

Casa Civil. Notícias. (2021). Governo do Estado de São Paulo, 2020. Disponível em: $<$ http://www.casacivil.sp.gov.br/sao-paulo-e-a-21a-maior-economia-do-

mundo/\#: :text=O\%20PIB\%20paulista\%20\%C3\%A9\%20maior,mercado\%20consumidor\%20da\%20 Am\%C3\%A9rica\%20Latina>; acesso em: 25 dez. 2021.

Dias Sobrinho, José. (2021). Avaliação e transformações da educação superior brasileira (1995-2009): do provão ao SINAES. Avaliação: Revista da Avaliação da Educação Superior, Campinas, v. 15, n. 1: 195-224, 2010. Disponível em: http://www.scielo.br/pdf/aval/v15n1/v15n1a11.pdf. Acesso em: 09 dez. 2021.

El País Brasil. (2018). "Anti-marxista" indicado por Olavo de Carvalho será ministro da Educação. Disponível em: <https://brasil.elpais.com/brasil/2018/11/22/politica/1542910509_576428.html>; acesso em>: 19 dez. 2021.

Falcão, Paula; Souza, Aline Batista de. (jan./mar. 2021). Pandemia de desinformação: as fake news no contexto da Covid-19 no Brasil. Revista Eletrônica de Comunicação, Informação \& Inovação em Saúde, Rio de Janeiro, v. 15, n. 1: 55-71. Disponível em: < https://www.arca.fiocruz.br/handle/icict/47085>. Acesso em: 26 dez. 2021.

Folha de São Paulo. Bolsonaro estimula população a invadir hospitais para filmar oferta de leitos. (Junho de 2020). Disponível em: <https://www1.folha.uol.com.br/cotidiano/2020/06/bolsonaroestimula-populacao-a-invadir-hospitais-para-filmar-oferta-de-leitos.shtml >; acesso em: 26 dez. 2021.

Folha de São Paulo. (Janeiro de 2022). Governo troca diretor de gestão do INEP após aplicação do ENEM 2021. Disponível em: <https://www1.folha.uol.com.br/educacao/2022/01/governo-troca-diretorde-gestao-do-inep-apos-aplicacao-do-enem-2021.shtml>; acesso em: 21 jan. 2022

Globo G1 (2021). Inep: Entenda a crise que levou à saída de 37 servidores do órgão responsável pelo Enem e como isso pode afetar o exame. Novembro de 2021. Disponível em: <https://g1.globo.com/educacao/noticia/2021/11/09/inep-entenda-a-crise-no-orgao-responsavel-peloenem-e-como-isso-pode-impactar-o-exame.ghtml>; acesso em: 19 dez. 2021.

Humanista - Laboratório da Faculdade de Biblioteconomia e Comunicação da UFRGS. (2021). Covid19: "Troca de ministros é sintoma de doença mais grave", afirma especialista em saúde coletiva. Março de 2021. Disponível em: <https://www.ufrgs.br/humanista/2021/03/25/covid-19-troca-de-ministros-esintoma-de-doenca-mais-grave-afirma-especialista-em-saude-coletiva/>; acesso em: 18 dez. 2021. 
IBGE. (2021). Agência de Notícias Releases. Disponível em: <https://censos.ibge.gov.br/2013-agenciade-noticias/releases/23200-em-2017-expectativa-de-vida-era-de-76-anos.html>; acesso em: 25 dez. $\underline{2021 .}$

IBGE. (2021). Estatísticas. São Paulo, 2021, Disponível em> <https://www.ibge.gov.br/estatisticas/sociais/populacao/25844-desigualdades-sociais-por-cor-ouraca.html?edicao=25845\&t=resultados $>$; acesso em: 25 dez. 2021.

IBGE. (2021). Agência de Notícias Sala de Imprensa. São Paulo, 2021. Disponível em: $<$ https://agenciadenoticias.ibge.gov.br/agencia-sala-de-imprensa/32596-cidade-de-sao-pauloconcentra-10-3-do-pib-do-pais-em-2019.html>; acesso em: 25 dez. 2021.

INEP. (2010). Guia de elaboração e revisão de itens. Ministério da Educação, Instituto Nacional de Estudos e Pesquisas Educacionais Anísio Teixeira, Brasília, DF. Disponível em: $<$ https://darnassus.if.ufrj.br/ marta/enem/docs_enem/guia_elaboracao_revisao_itens_2012.pdf >; acesso em: 17 dez. 2021.

INEP. (2021). Divulgados gabaritos preliminares do Enade 2021, Ministério da Educação, Instituto Nacional de Estudos e Pesquisas Educacionais Anísio Teixeira, Brasília, DF, 2021. Disponível em: <https://www.gov.br/inep/pt-br/assuntos/noticias/enade/divulgados-gabaritos-preliminares-do-enade2021>; acesso em: 17 dez. 2021.

Isto É. (12/2020). Bolsonaro sobre vacina da Pfizer: 'Se você virar um jacaré, é problema seu'. Disponível em: <https://istoe.com.br/bolsonaro-sobre-vacina-de-pfizer-se-voce-virar-um-jacare-eproblema-de-voce/>; acesso em: 26 dez. 2021.

Judensnaider, Ivy; Figueirôa, Silvia F. de M.; VILLAR, Renato Pacheco. (2021). Como as Teorias da Aprendizagem aparecem nas provas do ENADE?: Uma investigação para as Licenciaturas em Ciências e Matemática em 2017. Revista Internacional de Pesquisa em Didática das Ciências e Matemática: e021016-e021016, 2021. Disponível em: <https://periodicoscientificos.itp.ifsp.edu.br/index.php/revin/article/view/529>; acesso em: 18 dez. 2021.

Olabuenaga, J. I. R.; Ispizua, M. A. (1989). La descodificacion de la vida cotidiana: metodos de investigacion cualitativa. Bilbao, Universidad de deusto.

OPAS Organização Pan-Americana de Saúde. (2021). Histórico da pandemia de COVID-19. Disponível em: <https://www.paho.org/pt/covid19/historico-da-pandemia-covid-19>; acesso em: 12 dez. 2021.

PAHO Pan-American Health Organization. (2020). Perguntas frequentes sobre as vacinas candidatas contra a COVID-19 e os mecanismos de acesso. Versão 2, 27 de agosto de 2020. Disponível em: <https://iris.paho.org/handle/10665.2/52669>; acesso em: 12 dez. 2021.

PAHO Pan-American Health Organization. (2021). Caçadores de mitos sobre COVID-19. Disponível em: <https://www.paho.org/pt/cacadores-mitos-sobre-covid-19>; acesso em: 12 dez. 2021.

PAHO Pan-American Health Organization. (2021). Mitos e verdades vacinas COVID-19 - Coleção de redes sociais. Disponível em: <https://www.paho.org/pt/documentos/mitos-e-verdades-vacinas-covid19-colecao-redes-sociais>; acesso em: 12 dez. 2021.

Radio Senado. (2020). STF reconhece competência de estados e municípios em regras de isolamento. Brasil: DF. Disponível em: <https://www12.senado.leg.br/radio/1/noticia/2020/04/16/stf-reconhececompetencia-concorrente-de-estados-df-municipios-e-uniao-no-combate-a-covid-19>; acesso em: 18 dez. 2021. 
Richardson, R.J. (1989). Pesquisa social: método e técnicas. São Paulo, Atlas.

RNSP. (2020). Edição extraordinária do Mapa da Desigualdade indica CEP como fator de risco na pandemia. São Paulo: REDE NOSSA SÃO PAULO. Disponível em: <https://www.nossasaopaulo.org.br/2020/06/24/edicao-extraordinaria-do-mapa-da-desigualdadeindica-o-endereco-como-fator-de-risco-na-pan/>; acesso em: 25 dez. 2021.

RNSP. (2021). Mapa da Desigualdade 2021. São Paulo: REDE NOSSA SÃO PAULO, outubro de 2021. Disponível em: <https://www.nossasaopaulo.org.br/wp-content/uploads/2021/10/Mapa-DaDesigualdade-2021_Tabelas.pdf>; acesso em: 25 dez. 2021.

Rocha, Paula Del Ponte; Ferreira, Maira. (2017). Avaliação em larga escala e indicativos de qualidade na educação. Revista Educação Em Questão, UFRN, v. 55, n. 43: 139-161. Disponível em: https://periodicos.ufrn.br/educacaoemquestao/article/view/11809. Acesso em: 09 dez. 2021.

São Paulo. (2021). SP Contra o Novo Coronavírus: Boletim Completo. Governo do Estado de São Paulo, 2021. Disponível em: <https://www.seade.gov.br/coronavirus/>; acesso em: 18 dez. 2021.

Senado Federal. (2021). Relatório Final: CPI da Pandemia. Brasil: DF. Disponível em: <https://legis.senado.leg.br/comissoes/comissao?codcol=2441>; acesso em: 18 dez. 2021.

Vianna, Heraldo Marelim. (2003). Avaliações nacionais em larga escala: análises e propostas. Estudos em avaliação educacional, São Paulo, n. 27: 41-76. Disponível em: http://publicacoes.fcc.org.br/ojs/index.php/eae/article/view/2177. Acesso em: 09 dez. 2021.

WHO - World Health Organization. (2021). Coronavirus (COVID-19) DASHBOARD. Disponível em: <https://covid19.who.int/table>; acesso em: 12 dez. 2021. 